\title{
Self-treatment by adults during slow-onset exacerbations of asthma
}

\author{
Jakob J. Klein*, Job van der Palen, Susan van den Hof, Maroeska M. Rovers \\ Department of Pulmonary Medicine, Medisch Spectrum Twente, Enschede, The Netherlands
}

\begin{abstract}
Self-management plans are considered today an essential component of the management of asthma. The objective of the present study was (a) to explore patients' present practical knowledge of self-treatment of asthma, and (b) to provide an assessment of the effect of an educational program on this knowledge and self-treatment behaviour. Twenty four adults with asthma from the outpatient clinic of the Department of Pulmonary Medicine participated in a self-management program. They were provided with explanations on the symptoms and precipitating factors of their asthma, on its treatment with medication and their side-effects, and with personal written guidelines for self-adjustment of their medication. Prior to the program their practical knowledge of adequate self-treatment was investigated using a hypothetical scenario of a slow-onset asthma exacerbation. The effectiveness of the teaching and training program was evaluated by the change in knowledge prior to and 5 months after the program and self-reported behaviour of the participants at follow-up. (a) More than $60 \%$ of the patients lacked practical knowledge of self-treatment of a slow-onset exacerbation of asthma. (b) The educational program resulted in a significant increase $(47 \%)$ of this knowledge. (c) Actual self-treatment behaviour, as recorded by the patients 5 months after completing the educational program, was adequate in only two of ten patients, who experienced an exacerbation during the study period. Many adults with asthma are deficient in practical knowledge of self-treatment of a slow-onset exacerbation. This knowledge was significantly augmented by an educational program. Nevertheless actual self-treatment behaviour at follow-up was inadequate in the majority of patients. (C) 1997 Elsevier Science Ireland Ltd.
\end{abstract}

Keywords: Asthma; Self-treatment; Adult; Slow onset

\section{Introduction}

Prompt recognition and treatment of deteriorating asthma can reduce the morbidity and mortality from this disease [1]. Consequently, patients should be encouraged to monitor relevant symptoms and/or peak expiratory flow

\footnotetext{
*Corresponding author. Tel.: + 3153 4872610/4872619; fax: +31534872638 .
}

(PEF) and to adjust their therapy or seek medical assistance, when necessary. Self-management plans are considered today an essential component of the management of adult asthma, especially for the moderate and severe patients $[2,3]$.

Because increased knowledge alone is not sufficient for adequate self-management $[4,5]$, asthma education programs should not only provide knowledge but also contain motivational 
techniques that can assist in the translation of knowledge into behavioural practices which will improve therapeutic outcomes. One way to do this, is by increasing the patients' self-efficacy expectations regarding self-treatment of asthma. This is mainly enforced by letting them experience successful self-treatment behaviour and by observing this in others [6,7]; group educational sessions that address successful self-treatment behaviour in one of the participants (e.g. showing an actual graph of a patient with improved PEF's, after doubling the dose of inhaled steroids) could have the potential to do so.

Although also advocated in the Netherlands [8], a structured asthma self-management and self-treatment program has not yet been developed and tested. The development of a program appropriate for the needs of Dutch adults with asthma, necessitated an insight into their present self-treatment habits. In a previous study by our group, results of which will be published elsewhere, a self-administered questionnaire was mailed to all subjects with asthma in a large city in the Netherlands. One of the questions was a hypothetical scenario of a slow-onset asthma exacerbation. Analysis of the answers showed that only a minority of the responders was familiar with adequate self-treatment (increase or start of inhaled or oral steroids in case of an exacerbation). The objective of the present study was to evaluate the effect of an educational program on patients' practical knowledge regarding and actual self-treatment behaviour during a slow-onset exacerbation of asthma.

\section{Methods}

The study was approved by the hospital's Ethics Committee.

\subsection{Patient population}

In February 1995, 36 subjects were randomly selected from the outpatient database of the Department of Pulmonary Medicine of the Medisch Spectrum Twente in Enschede. Inclusion criteria were stable asthma during the last 6 weeks, use of inhaled steroids and age between $18-65$ years. The patients were offered to participate in a self-management program. Of the 36 patients approached, 24 agreed to participate and were included in the present study.

\subsection{Intervention}

During a 2 week run-in period the patients recorded their morning and evening PEF, symptoms and medication use in a diary. From these records, the Personal Best Morning PEF Value (PBV) before bronchodilator use was determined. After the run-in period all participants were assigned to groups of 5-8 patients, and each group participated during the following four weeks in four 90 min educational sessions. During these sessions, an experienced nurse provided explanations on the symptoms and precipitating factors of asthma, as well as on its treatment and the possible side-effects of the drugs. During the last session patients received personal written guidelines for the self-adjustment of the medication. They were asked to measure their PEF once a week on a fixed day and daily if they experienced an increase in symptoms. Patients were told to inhale their drugs as prescribed, as long as they were almost symptom-free or their PEF was above $80 \%$ of their PBV. If PEF fell between 60 and $80 \%$ of their PBV on two consecutive mornings, patients were instructed to double the dose of their inhaled steroids until they returned to values above $80 \%$, after which they were to continue the doubled dose for another week. Below $60 \%$ of their PBV, patients had to start a 1 week course of oral prednisolone. Patients were to contact their chest physician if PEF values fell below 50\% of their PBV.

\subsection{Questionnaire}

Prior to the intervention a self-administered questionnaire was given to the participants. One of the questions was a hypothetical scenario of a slow-onset asthma exacerbation (see Appendix A). The proportion of responders indicating adequate self-treatment was determined. Selftreatment was considered adequate if the patient 
indicated either that he or she would use more inhaled or oral steroids, or that he or she would start oral steroids or additional medication [911].

Follow-up was 5 months. Patients completed again the 2 week peak-flow, symptom, and medication diary together with the self-administered questionnaire.

\subsection{Analysis of the results}

Answers to the questionnaire prior to and 5 months after the self-management program were compared by means of the Chi-square test or Fisher's Exact test. The answers 5 months after the intervention were also compared with the actual self-treatment behaviour, extracted from patients' diaries at 5 months' follow-up.

\section{Results}

Responses to the questionnaire were obtained from 23 out of 24 patients before the teaching program, and from 22 patients 5 months later (Table 1). Although the vast majority of subjects prior to the intervention indicated that they would act in any way $(83 \%)$ and would use more daily medication (84\%), only 9 subjects would have increased inhaled or oral steroids and only one person would have started oral steroids. Practical knowledge of adequate self-treatment in case of a slow-onset exacerbation increased significantly from $39 \%$ before the program to $86 \% 5$ months after its completion $(P=0.001)$.

Nineteen patients recorded their PEF and medication in a diary during the last 2 weeks of the 5 months follow-up period (Table 2). Nine patients had PEF values above $80 \%$ of their PBV throughout these 2 weeks. Of the remaining ten patients, seven had PEF values between 60 and $80 \%$ of their PBV. Only two of these seven subjects doubled the dose of inhaled steroids, one increased the dose only a little, while four did not change their medication. None of the four patients in whom the PEF declined below $60 \%$ of their PBV (including one who had correctly doubled the dose of inhaled steroids

Table 1

Self-treatment in a slow-onset exacerbation: answers to a hypothetical scenario by 23 subjects before, and by 22 subjects 5 months after an educational program for self-management of asthma

\begin{tabular}{lccc}
\hline & Before $^{1}$ & After $^{1}$ & $P$ value $^{2}$ \\
\hline 1. Would you act in any way? & $19(83)$ & $21(95)$ & 0.171 \\
2a. More use of daily medication? ${ }^{3}$ & $16(84)$ & $19(90)$ & 0.550 \\
2b. If yes, inhaled and/or oral steroids? & $9(56)$ & $19(100)$ & $4(19)$ \\
3a. Use of additional medication? & $3(16)$ & $3(75)$ & 0.001 \\
3b. If yes, oral steroids? & $1(33)$ & $19(86)$ & 0.787 \\
Adequate self-treatment $^{4}$ & $9(39)$ & 0.270 \\
\hline
\end{tabular}

, number (\%) of patients responding 'yes'.

${ }^{2}$, Fisher's exact or Chi-square test.

3 , only answered by patients acting in any way (question $1=$ yes).

${ }^{4}$, self-treatment was considered adequate, if questions $2 \mathrm{~b}$ and/or $3 \mathrm{~b}$ were answered 'yes'.

Table 2

Self-reported self-treatment behaviour by 19 subjects 5 months after an educational program for self-management of asthma

\begin{tabular}{lll}
\hline Personal Best Peakflow value & Number of patients & $\begin{array}{l}\text { Number of patients who increased } \\
\text { medication according to } \\
\text { guidelines }\end{array}$ \\
\hline $80-100 \%$ & 9 & - \\
$60-80 \%$ & $7^{*}$ & 2 \\
$<60 \%$ & $4^{*}$ & 0 \\
\hline
\end{tabular}

*, one subject doubled the dose of inhaled steroids between $60-80 \%$ but did not start oral steroids $<60 \%$. 
when his PEF was between 60 and $80 \%$ of his $\mathrm{PBV}$ ) added oral prednisolone to his/her treatment.

\section{Discussion}

The present study revealed three main findings. Firstly, before the educational program, practical knowledge of adequate self-treatment in case of slow-onset exacerbation of asthma among 23 adults, using inhaled steroids, was insufficient. Secondly, an educational program resulted in a significant increase in practical knowledge of correct self-treatment of exacerbations from $39 \%$ before the program to $86 \% 5$ months after its completion. Lastly, actual selftreatment behaviour, as recorded by the patients at 5 months' follow-up, was adequate in only 2 out of 10 patients. The first result of insufficient practical knowledge of adequate self-treatment behaviour was also found in our previously mentioned survey among adults with asthma in the city of Enschede (population 146000 ). In 1994 we obtained from all pharmacies in the city a list of persons who had used inhaled medication in 1993. The same self-administered questionnaire as used in the present study, was mailed to them. The anonymous answers of 1262 respondents, who had been diagnosed by their physician as having asthma, to the question concerning self-treatment in a hypothetical scenario of a slow onset exacerbation could be analysed. This rendered a nearly similar percentage of patients $(37 \%)$ with adequate knowledge of self-treatment as in the 23 patients from the outpatient clinic.

Our findings are consistent with those of three other surveys of patients' responses to a hypothetical scenario of a slow-onset exacerbation. Inadequate knowledge of the appropriate selftreatment behaviour was found in $65 \%$ of 210 asthmatic adults, as assessed by interviews and questionnaires [12], and in $81 \%$ of 5568 persons with an asthma exacerbation, as assessed by questionnaire [13]. Kolbe et al. [14] reported the results of interviews of 80 patients with moderate to severe asthma attending a hospital-based asthma clinic in New Zealand. Even after completion of an educational program with guidelines for self-adjusted treatment according to changes in the PBV, only $42 \%$ of the interviewees indicated that they would increase the inhaled steroids. Inadequate self-treatment was also reported in four other studies of hospitalized patients for severe exacerbations of asthma. Thus, 41 of 75 British patients failed to alter their medication prior to admission, even though the deterioration occurred in the course of 7 days or more [15]. Twenty Canadian patients with near fatal asthma reported to have used only half of their prescribed amount of inhaled steroids during the 2 weeks prior to admission [16]. Of 131 Scottish patients only $36 \%$ had used oral steroids during the month before admission, although $70 \%$ of them had been confined to bed [17]. Only 5\% of 127 Australian patients with nearfatal asthma reported initiating or increasing oral steroids at the time of the severe exacerbation [18].

Two other studies attempted to gain an insight into the actual, rather than reported, behaviour, using memory capable PEF-meters and inhalers. Chmelik [19] found that 10 of 20 subjects underused their inhaled and/or oral steroids, despite adequate general knowledge about self-treatment of asthma. We have already reported that electronic monitoring of the short-term compliance of our patients during the first 4 weeks after our educational self-management program revealed that only three of ten subjects with PEF values between $60 \%$ and $80 \%$ of PBV doubled their inhaled steroids, 4 increased the dosage somewhat, while three did not change their steroid medication [20]. Unfortunately we were not able to use the memory capable PEF-meters at the end of the study.

This study once again confirms that acquisition of increased practical knowledge is not necessarily followed by the initiation of appropriate action (increase inhaled or oral steroids or add oral steroids in the setting of a slow-onset exacerbation of asthma) [4,5].

The information gathered from this study 
helped us to alter several aspects of the selfmanagement and self-treatment educational program for Dutch adults with asthma. In the new program we place particular emphasis on doubling the dose of inhaled steroids when PEF falls below $80 \%$, and patients are instructed to stay at this level for a fixed period of 14 days. Furthermore we stress even more intensively the need for starting a short course of oral steroids (1 week) with PEF's below $60 \%$ of their PBV, and that not doing so could lead to a serious attack. Finally, we inform them that such a short boost of oral steroids does not produce serious sideeffects. This "new" program has been used in a randomised controlled self-management trial, incorporating self-treatment guidelines. One year follow-up results of 245 participants are presently being analysed.

\section{Acknowledgements}

The authors acknowledge the help and support of the Netherlands Asthma Foundation (grant 94-52), GlaxoWellcome, and the OostNederland Health Care Insurance Fund, and thank the pulmonary-function technicians, chest physicians, and clerical staff of the Department of Pulmonary Medicine, who did so much to bring this work to a successful conclusion.

\section{Appendix A}

Question: If your asthma gets slowly worse (in the course of days or weeks), how would you act? (Choose as many answers as you feel appropriate)

a) I would wait for the worsening symptoms to yes/no disappear.

If no:

b) I would use my daily medication more often. yes/no If yes: Which medication?

c) I would use additional medication. yes/no If yes: Which medication?

\section{References}

[1] Rea HH, Sears MR, Beaglehole R. Lessons from the national asthma mortality study: circumstances surrounding death. New Zealand Med J 1996;100:10-3.

[2] National Heart Lung and Blood Institute. Global strategy for asthma management and prevention. NHLBI/WHO Workshop Report. Publication no. 95-3 ed. Bethesda, MA: National Institutes of Health, 1995.

[3] The British guidelines on asthma management: 1995 review and position statement. Thorax 1997;52:S1-S21.

[4] Clark NM. Asthma self-management education; research and implications for clinical practice. Chest 1989;95:1110-3.

[5] Hilton S, Sibbald B, Anderson HR, Freeling P. Controlled evaluation of the effects of patient education on asthma morbidity in general practice. Lancet 1986;26-9.

[6] Bandura A. Social foundations of thought and action: A social cognitive theory. Englewood Cliffs, NJ: Prentice Hall, 1986.

[7] Pieterse GC, Taal E, Seydel ER. Psychosociale aspecten van CARA: Ziektelast en interventiestrategiën voor patiëntenvoorlichting (psychosocial aspects of chronic non-specific lung disease: burden of disease and intervention strategies for patient education). Enschede: Universiteit Twente, 1993.

[8] Geijer RRM, van Hensbergen W, Bottema BJAM et al. NHG-Standaard Astma bij, Volwassenen: Behandeling (Dutch General Practice guidelines asthma in adults). Huisarts Wet 1997;40:443-54.

[9] Beasley R, Cushley M, Holgate ST. A self management plan in the treatment of adult asthma. Thorax 1989;44:200-4.

[10] D'Souza W, Crane J, Burgess C et al. Community-based asthma care: trial of a "credit card" asthma self-management plan. Eur Respir J 1994;7:1260-5.

[11] Lahdensuo A, Haahtela T, Herrala J et al. Randomised comparison of guided self management and traditional treatment of asthma over one year. $\mathrm{Br}$ Med J 1996;312:748-52.

[12] Sibbald B. Patient self care in acute asthma. Thorax 1989;44:97-101.

[13] Marks GB, Simpson J, Burney PGJ, Webb J. Asthma in Greenwich: self-management of exacerbations. Eur Respir J 1994;7:252s.

[14] Kolbe J, Vamos M, James F, Elkind G, Garrett J. Assessment of practical knowledge of self-management of acute asthma. Chest 1996;109:86-90.

[15] Blainley D, Lomas D, Beale A, Partridge MR. The cost of acute asthma - how much is preventable?. Health Trends 1990;22:151-3.

[16] Turner MO, Crump S, Contreras GR, Vedal S, Bai T, FitzGerald JM. A prospective evaluation of risk factors for near fatal asthma: Clinical characteristics. Am J Respir Crit Care Med 1994;149:A192. 
[17] Osman LM, Friend JAR, Legge JS, Douglas JG. When do patients contact doctors?. Eur Respir J 1994;7:141s.

[18] Campbell DA, Luke CG, McLennan G et al. Near-fatal asthma in south Australia: Descriptive features and medication use. Am J Respir Crit Care Med 1996;151:A473.

[19] Chmelik F, Doughty A. Objective measurements of compliance in asthma treatment. Ann Allergy 1994;73:527-32.

[20] van der Palen J, Klein JJ, Rovers MM. Compliance with inhaled medication and self-treatment guidelines following a self-management programme in adult asthmatics. Eur Respir J 1997;10:652-7. 